\title{
An Investigation of a Multi-Layered Oscillating Heat Pipe Additively Manufactured from Ti-6Al-4V Powder
}

\author{
Submitted to:
}

\section{International Journal of Heat and Mass Transfer}

Omar T. Ibrahim ${ }^{1}$, J. Gabriel Monroe ${ }^{1}$, Scott M. Thompson ${ }^{2, \dagger}$, Nima Shamsaei², Hassina Bilheux ${ }^{3}$, Alaa Elwany ${ }^{4}$, Linkan Bian ${ }^{5}$ 


\begin{abstract}
A laser powder bed fusion (L-PBF) additive manufacturing (AM) method was employed for fabricating a multi-layered, Ti-6Al-4V oscillating heat pipe (ML-OHP). The 50.8 x $38.1 \mathrm{x}$ $15.75 \mathrm{~mm}^{3}$ ML-OHP consisted of four inter-connected layers of circular mini-channels, as well an integrated, hermetic-grade fill port. A series of experiments were conducted to characterize the ML-OHP thermal performance by varying power input (up to $50 \mathrm{~W}$ ), working fluid (water, acetone, Novec ${ }^{\mathrm{TM}} 7200$, and n-pentane), and operating orientation (vertical bottom-heating, horizontal, and vertical top-heating). The ML-OHP was found to operate effectively for all working fluids and orientations investigated, demonstrating that the OHP can function in a multilayered form, and further indicating that one can 'stack' multiple, interconnected OHPs within flat media for increased thermal management. The ML-OHP evaporator size was found to depend on the layer-wise heat penetration which subsequently depends on power input and the ML-OHP design and material selection. Using neutron radiography, electron scanning microscopy and surface metrology, the ML-OHP channel structure was characterized and found to possess partially-sintered Ti-6Al-4V powder along its periphery. The partially-sintered channel surface, although a byproduct of the L-PBF manufacturing process, was found to behave as a secondary wicking structure for enhanced capillary pumping and wall/fluid heat transfer within the OHP. With the newfound capabilities of AM, many high heat flux thermal management devices, specifically those that employ mini- or micro-channels, can be 're-invented' to possess embedded channels with atypical geometries, arrangements and surface conditions.
\end{abstract}

\title{
Keywords
}

Additive manufacturing; heat exchangers; wicking structure; minichannels; pulsating heat pipe; heat transfer enhancement; laser sintering; heat spreader

\section{Nomenclature}

Bo Bond number

$c_{\mathrm{p}} \quad$ isobaric specific heat capacity, $\mathrm{kJ} / \mathrm{kg} \cdot \mathrm{K}$ 


$$
\begin{array}{ll}
g & \text { acceleration due to gravity, } \mathrm{m} / \mathrm{s}^{2} \\
h_{\mathrm{lv}} & \text { enthalpy of vaporization, } \mathrm{kJ} / \mathrm{kg} \\
j & \text { thermocouple location } \\
k & \text { thermal conductivity, } \mathrm{W} / \mathrm{m} \cdot \mathrm{K} \\
P & \text { power input, } \mathrm{W} \\
r & \text { radius, } \mathrm{m} \\
T & \text { time-averaged, steady-state temperature, }{ }^{\circ} \mathrm{C}
\end{array}
$$

\section{Greek symbols}

$\mu \quad$ dynamic viscosity, $\mu \mathrm{Pa} \cdot \mathrm{s}$

$\rho \quad$ density, $\mathrm{kg} / \mathrm{m}^{3}$

$\psi \quad$ thermal resistance, ${ }^{\circ} \mathrm{C} / \mathrm{W}$

$\sigma \quad$ surface tension, $\mathrm{N} / \mathrm{m}$

\begin{tabular}{ll}
\multicolumn{2}{l}{ Subscripts } \\
avg & average \\
c & critical \\
eff & effective \\
H & hydraulic \\
l & liquid \\
V & vapor
\end{tabular}

\section{Introduction}

The miniaturization and enhancement of electronics packaging schemes continue to challenge the design and engineering of compact heat dissipation systems for thermal management [1]. With heat fluxes nearing $1 \mathrm{~kW} / \mathrm{cm}^{2}$ being realized and conventional, single-phase thermal management techniques are no longer viable. This has resulted in disruptive technology innovations such as near-junction/intra-cooling [2,3] and two-phase, (far-junction) surfacemounted heat spreaders/sinks [4,5]. With regard to 'far-junction' thermal management, methods are continually sought for effectively spreading thermal energy over relatively thin media to achieve their near-isothermal surface opposite to the adjoined heat source. One such device for 
high heat flux thermal spreading is the thermal ground plane (TGP). The TGP is a surfacemounted, two-phase heat spreader that operates passively [3,6,7]; relying on capillary structures such as porous/sintered media and mini/micro-channels for cyclic fluid pumping. Some examples of TGPs include flat heat pipes, vapor chambers, oscillating (or pulsating) heat pipes (OHPs) and other hybrid two-phase cooling technologies [5,8-12]. The mounting of a TGP typically requires that minimal stress occurs at the source-contacting interface to ensure minimal damage to heatdissipating electronics. To this end, the heat source and TGP coefficient of thermal expansion (CTE) are often sought to be 'matched' for reducing interfacial stresses.

The OHP, as shown schematically in Fig. 1, is a partially-filled capillary structure that meanders, in a serpentine-fashion, through a heat source (i.e. evaporator) and sink (i.e. condenser) $[13,14]$. It can take the form of media-embedded, mini/micro-scale channels (i.e. a flat plate OHP a.k.a. FP-OHP) or capillary tubing (i.e. a tubular OHP); each requiring a hermetic seal for optimal operation. Upon introduction of a sufficient temperature difference, or heat flux, the fluid inside the OHP vaporizes and expands unevenly along various sections of its evaporator resulting in its 'start-up'. Vapor pressure builds due to sensible heating and results in a non-uniform, oscillatory pressure field forming against liquid volumes. The oscillatory fluid motion, combined with phasechange heat transfer, allows for cyclic, fluid-driven heat transport from the OHP evaporator to the condenser. This cyclic phase change is typically evidenced by an OHP surface temperature field that oscillates with respect to time $[15,16]$. The type and amount of working fluid, channel/tube dimensions, number of channel/tube turns (a.k.a. 'U-turns', bends), operating orientation with respect to gravity, and heating/cooling areas are some of the many design/operating parameters affecting OHP thermal performance $[17,18]$. 


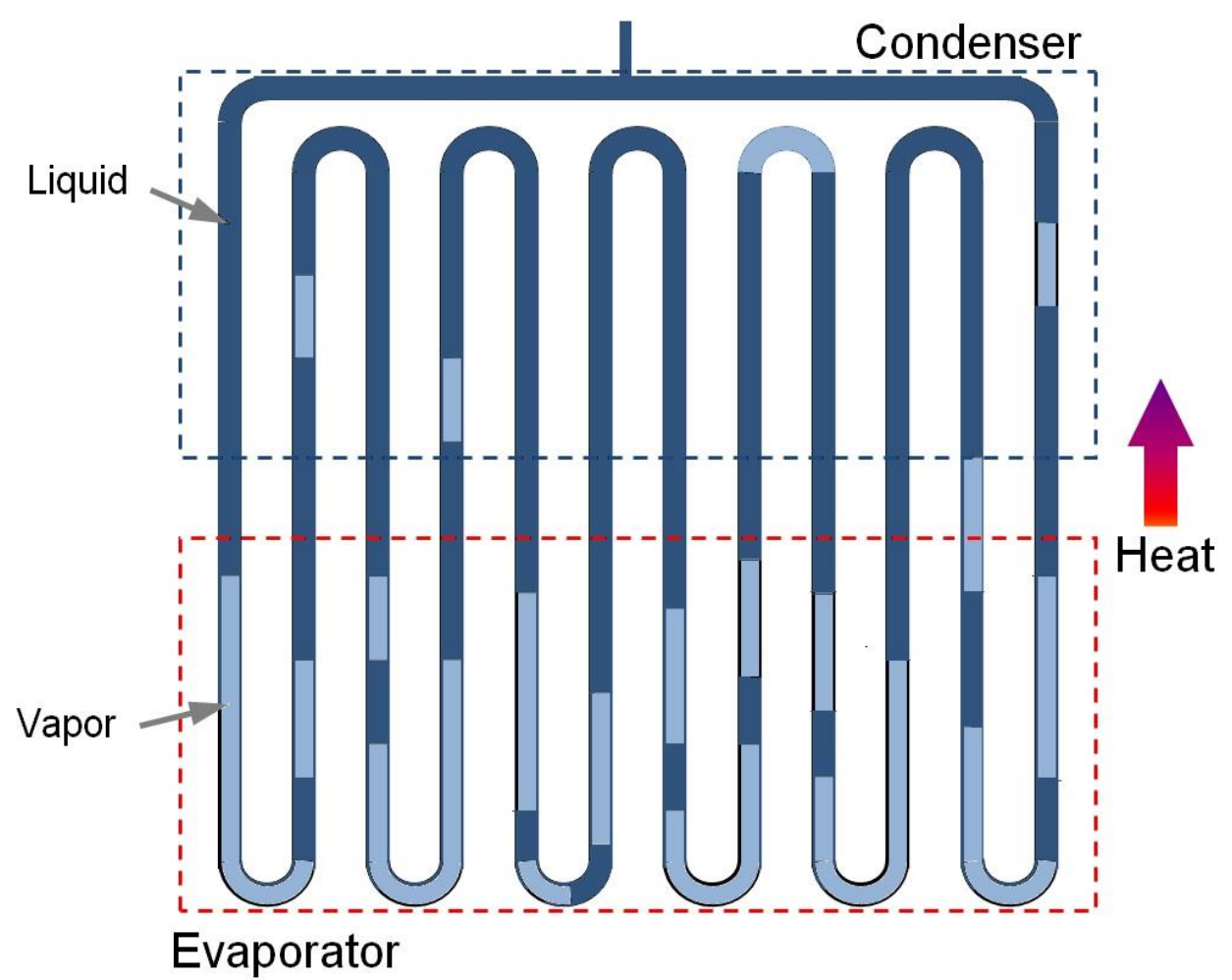

Fig. 1 Schematic of typical liquid/vapor distribution within an oscillating heat pipe (OHP) consisting of uniformly-sized evaporator and condenser.

The working fluid selected for the OHP must demonstrate wicking behavior as governed by the OHP channel/tube hydraulic radius, $r_{\mathrm{H}}$, and operating environment (e.g. gravity). Conditions for capillarity, and thus effective OHP operation, can be estimated via the Bond number, Bo, i.e.:

$$
\mathrm{Bo}=\frac{r_{\mathrm{H}}^{2} \Delta \rho_{\mathrm{lv}} g}{\sigma} \lesssim \mathrm{Bo}_{\mathrm{c}}
$$

where $\sigma$ is the liquid-to-vapor surface tension, $\Delta \rho_{\mathrm{lv}}$ is the difference in density between the liquid and vapor phases, and $\mathrm{Bo}_{\mathrm{c}}$ is the critical Bond number for capillarity and can range between $0.8-$ $1.0[14,19]$.

The thermophysical and rheological properties of the utilized working fluid dictate OHP thermal performance. A fluid's surface tension strongly influences evaporation heat transfer [20], as well as the pressure gradient along the OHP flow path [18]. Fluids with a lower latent heat of vaporization and dynamic viscosity tend to provide for slower flow speeds, moderate heat transfer and lower OHP start-up powers [18,21,22]. A fluid's specific heat capacity influences its single- 
phase heat transfer during oscillatory, forced convection within an operating OHP. Since the majority of OHP heat transfer is typically sensible [23], the specific heat capacity and thermal conductivity are thus important thermal properties of the working fluid. A fluid with a vapor pressure highly sensitive to temperature is desirable for increasing an OHP's pumping capability - which is needed for assisting its start-up and consistent operation [18]. Taft et al. [24] demonstrated that the latent heat of vaporization, surface tension, and density of working fluids play an important role in OHP start-up and that viscous fluids provide more dampened temperature oscillations during OHP operation. Both the surface tension and density of a working fluid can affect OHP channel sizing for various micro-to-macro gravity environments (i.e. the Bo is gravity dependent) [19,25]. In general, fluids with low dynamic viscosity and latent heat of vaporization reduce the heat input required for OHP start-up by minimizing channel pressure drop [18,24]. Fluids with a smaller latent heat of vaporization can improve OHP performance by providing higher oscillating velocities (caused via higher vapor pressure).

Since OHP operation depends on the dominance of surface tension forces for ensuring capillary flow, the magnitude and direction of gravity will, in general, affect OHP thermal performance [13,17,25-30]. For terrestrial gravity environments (i.e. $1 g$ ), this dependence is often demonstrated experimentally by altering the OHP's operating orientation and relative positioning of its evaporator and condenser. An OHP in the vertical bottom-heating orientation (or 'mode') is descriptive of it being collinear with the gravity vector and its condenser above its evaporator; while an OHP in the horizontal orientation indicates that the OHP is perpendicular to the gravity vector. Riehl demonstrated that, for a constant fill ratio of 50\%, the sensitivity of an OHP's thermal performance to working fluid is exaggerated when the OHP is operating in the horizontal orientation [31]. This was demonstrated for a variety of working fluids, including: water, methanol, acetone, isopropyl alcohol, and ethanol. Variation of the OHP's effective thermal conductivity was found to vary by $\pm 19 \%$ when changing working fluids with the OHP in the bottom-heating mode, while the variation was $\pm 53 \%$ in the horizontal orientation.

To combat adverse gravity effects, for a given working fluid, one can alter the OHP structure and design, by, for example: increasing the number of turns [22], decreasing the channel diameter [18], using check-valves [32] and/or increasing the number of channel layers [22,33,34]. The number of channel layers is of interest for high heat flux thermal management, as well as gravity combatting, since this allows the OHP structure to overlap itself, thus becoming denser. 
Traditional OHP designs consist of a channel structure that remains in one plane, while multilayered OHPs (ML-OHPs) consist of a channel that meanders through multiple planes. By having a multi-directional channel structure, the ML-OHP can be less prone to gravity force and provide for a wider range of heating/cooling boundary conditions [22].

Thompson et al. experimentally investigated a copper, flat-plate ML-OHP (two layers) filled with either water or acetone [32,33]. In addition to varying the working fluid and orientation, the heating area, and thus OHP evaporator size, was varied. It was demonstrated that increasing the OHP channel layer number could allow for higher heat flux mitigation (i.e. $~ 300 \mathrm{~W} / \mathrm{cm}^{2}$ was observed) and an increased range of operating orientations in which thermal performance is not altered. The orientation-dependence of the ML-OHP was shown to become stronger as the heating area was reduced, and this suggests that the OHP design investigated may have not been entirely optimal. Borgemeyer et al. experimentally investigated a tubular ML-OHP (two layers) filled 50\% with water and observed exceptional thermal performance ( $400 \mathrm{~W}$ capability) which was attributed to the OHP multi-layer design [35]. The evaporator-to-condenser temperature difference was found to decrease as power input increased. Smoot and Ma investigated the effect of channel layer number (up to three) and operating orientation on the thermal performance of a $229 \times 76 \times 13 \mathrm{~mm}^{3}$ copper ML-OHP [34]. The device consisted of a single-layer OHP brazed between a double-layer, interconnected OHP; creating two independent closed-loop structures that were either partially filled with water (at 50\%) or remained empty. The results demonstrated that the utilization of more channel layers can significantly increase the OHP heat transfer capability (i.e. $\sim 8 \mathrm{~kW}$ ). It was further confirmed that the utilization of an ML-OHP with interconnected channels between layers provides for less sensitivity to operating orientation. In contrast, a MLOHP with independent/stacked single-plane channel circuits is more prone to operating orientation limitations, but can have a reduced start-up power requirement.

To date, ML-OHPs have been fabricated using traditional manufacturing methods, in which mini-channels are milled/etched and then cover plates are either mechanically or metallurgically (e.g. furnace brazing) attached for sealing purposes. While these methods are proven means for manufacturing single- or double-layer OHPs, the fabrication of a ML-OHP with interconnected channels exceeding two layers is challenging; especially while maintaining hermetic-grade channel encapsulation. The geometry and complexity of the OHP channel structure is also severely constrained by manufacturing capability, available resources and time. 
Although ultrasonic consolidation (UC) has been demonstrated as a successful means for fabricating aluminum OHPs [36], its utility for realizing highly-complex ML-OHPs and other types of TGPs remains at question.

Additive manufacturing (AM) is an appealing method for generating complex, metallic components from the ground-up directly from computer-sourced solid models (i.e. CAD). For metals, AM is commonly accomplished by the repetitious melting and solidification of metallic powder via directed energy in the form of a laser or electron beam. One common technique for the AM of metals is Laser Powder Bed Fusion (L-PBF) [37]. During L-PBF, successive solid layers of a part are formed by uniformly distributing and selectively fusing (via a laser) a bed of metallic powder under an inert protective atmosphere.

The use of L-PBF for generating application-tailored components is currently being realized in the biomedical and aerospace industries [38,39]. Structures with high degrees of geometric complexity are readily manufacturable, as un-melted particles within the L-PBF powder bed structurally support subsequent layers during their deposition; allowing for the fabrication of internal features and channels. With regard to OHPs, L-PBF provides new design options for channel geometry, number of channel layers, working material (i.e. materials other than copper or aluminum), surface features, alternate hermetic sealing methods and more. As an illustrative example, L-PBF allows one to construct an OHP with six layers of triangular channels parallel to various, tilted planes. With regard to fabricating surface-mounted heat sinks for electronics cooling, AM also provides a unique opportunity to manufacture heat transfer devices with bettermatching CTEs and higher melting temperatures. Although various AM methods have been proven successful in building Ti-6Al-4V components worthy for application, the mechanical integrity of such components is still relatively unknown and this is important when considering their use in high pressure or high thermal/mechanical cycling applications [40-43].

In this study, a novel high-temperature, CTE-matching material desirable for many applications - Ti-6Al-4V - is utilized for fabricating a ML-OHP with four interconnected layers of circular mini-channels via L-PBF. The ML-OHP design and manufacture are discussed and then followed by details of the experimental setup and procedure. Results demonstrating the thermal performance of the ML-OHP, as well as its internal channel surface condition, are then provided. 


\section{Prototype Design and Manufacturing}

A titanium alloy (Ti-6Al-4V) ML-OHP, shown in Error! Reference source not found.2, was manufactured layer-by-layer atop a $10 \times 10 \times 1 \mathrm{~cm}^{3}$ titanium platen within an argon purged L-PBF system (ProX 100 ${ }^{\mathrm{TM}}$ ) equipped with a $50 \mathrm{~W}$ fiber laser [44]. Gas atomized Ti-6Al-4V spherical particles (ASTM B347 Grade 5), with a diameter range of 15-45 $\mu \mathrm{m}$, were utilized in their as-received condition. The $50.80 \times 38.10 \times 15.75 \mathrm{~mm}^{3}$ ML-OHP consisted of four interconnected, horizontal layers of circular mini-channels - forming one closed, continuous loop. Using Eq. (1), the channel diameter was selected as $\varnothing \cong 1.52 \mathrm{~mm}$ to ensure capillarity of the multiple working fluids investigated. Ti-6Al-4V was chosen for the manufacture of the ML-OHP due to its proven additive-manufacturability and thermal expansion properties, i.e. CTE. Unlike the CTEs of traditional heat transfer materials such as copper $\left(\sim 17 \times 10^{-6} \mathrm{~K}^{-1}\right)$ and aluminum $(\sim 23$ x $\left.10^{-6} \mathrm{~K}^{-1}\right)$, Ti-6Al-4V has a CTE $\left(\sim 9 \times 10^{-6} \mathrm{~K}^{-1}\right)$ closer in magnitude to that of silicon $\left(\sim 3 \times 10^{-6}\right.$ $\left.\mathrm{K}^{-1}\right)$, a common semiconductor material used in integrated circuits.
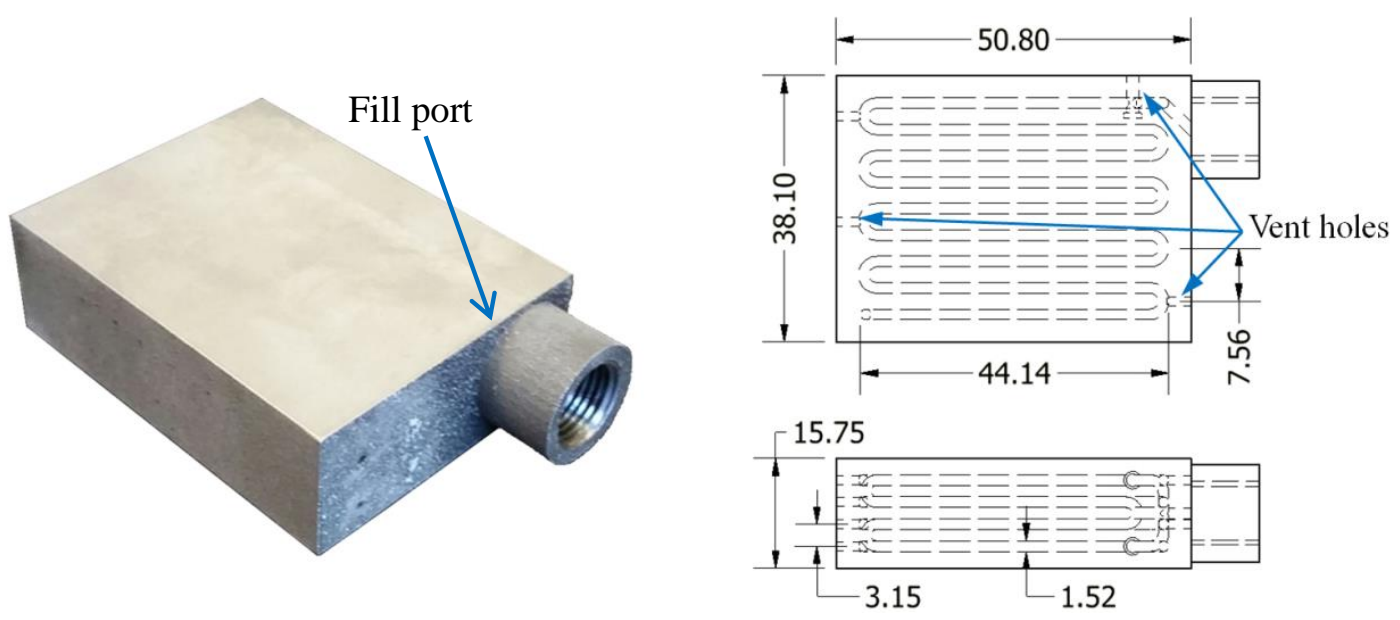

Fig. 2 Ti-6Al-4V ML-OHP with fill port and vent holes: (left) photograph after milling of faces and (right) dimensioned drawings (in millimeters).

Manufacturer-suggested process parameters for Ti-6Al-4V were employed to fabricate the ML-OHP with minimal porosity, including a laser power and scanning speed of $49 \mathrm{~W}$ and $40 \mathrm{~cm} / \mathrm{s}$, respectively. The nominal powder layer thickness and hatch distance (distance between adjacent laser passes within the same layer) used during fabrication were $70 \mu \mathrm{m}$ and $30 \mu \mathrm{m}$, respectively. The ML-OHP was built vertically upward; with the majority of its channel structure perpendicular 
to the build plate. Parallel laser scans were performed at $45^{\circ}$ angles while depositing each new layer of material. After fabrication, the ML-OHP was sheared off the build plate using electrical discharge machining (EDM).

Parts fabricated via L-PBF are prone to possessing relatively rough surfaces due to powder size variation, partially melted powder remaining at the edges, and potential balling phenomena at the trailing melt pool. Hence, the as-built ML-OHP had two of its sides faced (via end-milling) to obtain smoother surfaces for better contact with heating/cooling blocks during experimentation. A photograph of the post-PBF, machined ML-OHP is provided in Fig. 2. The encapsulated, unmelted powder within the closed-loop channel structure was sought for removal via a depowdering process; hence, nine vent holes (two at $\varnothing 1.83 \mathrm{~mm}$ and seven at $\varnothing 1.27 \mathrm{~mm}$ ) were drilled (and tapped) into the sides of ML-OHP channel layers. Powder was forced out of the MLOHP, layer-by-layer, by supplying pressurized air ( 1 MPa) through the vent holes. After depowdering each layer, the vent holes were sealed using titanium screws (0-80 UNF or 2-56 UNC threaded plugs), which were secured in place with thread locker (Loctite $\left.{ }^{\circledR} 222\right)$. The fill port $(\varnothing$ $3.18 \mathrm{~mm}, 1 / 8 \mathrm{NPT}$ ), protruding from the side of the ML-OHP as shown in Fig. 2, was tapped and a vacuum-grade fitting (Swagelok ${ }^{\circledR}$ SS-1-UT-1-2) was installed.

A phosphorous-deoxidized copper (alloy 122) tube (0.8 mm ID) was connected to the fill port, and the ML-OHP was connected in-line with a vacuum pump (Fisher Scientific Maxima C Plus Model M8C) assembly. The ML-OHP internal channel structure was repetitiously flushed with acetone (99.5\% purity) for removal of excess powder and oxide. Prior to the introduction of the working fluid, the fitted ML-OHP assembly was confirmed to hold a vacuum for a prolonged period of time by monitoring the pressure (MKS INC 910 pressure transducer, $\pm 5 \%$ accuracy) of the vacuum pump/heat pipe assembly. To investigate the effects of working fluid, approximately $70 \%( \pm 2 \%)$ of the heat pipe channel was filled with either: high performance liquid chromatography (HPLC)-grade water (Fisher Scientific W5SK-4, 1 g/mL density, 100\% purity), HPLC-grade acetone (Fisher Scientific A949-4, $0.7857 \mathrm{~g} / \mathrm{mL}$ density, 99.5\% purity), n-pentane (Aqua Solutions P1033-4L, $0.63 \mathrm{~g} / \mathrm{mL}$ density, 99\% purity) or Novec ${ }^{\mathrm{TM}} 7200$ (3M, $1.43 \mathrm{~g} / \mathrm{mL}$ density, standard purity). All working fluids were de-gassed and 'back-filled' into the evacuated ML-OHP ( 3 Pa vacuum) to prevent air from adversely affecting its thermal performance. After filling the ML-OHP, its charging tube was pneumatically crimped to ensure a hermetic seal. 


\section{Experimental Setup and Procedure}

The ML-OHP was experimentally characterized for thermal performance using a setup shown schematically in Fig. 3. In order to determine the effects of gravity, the device was suspended in an insulated, rotatable test frame for accomplishing horizontal (i.e. parallel to ground), vertical bottom-heating and vertical top-heating orientations. As shown in Fig. 3Error! Reference source not found., the ML-OHP evaporator and condenser were located on opposing faces and sides. This heating/cooling configuration was selected for maximizing the layer-wise heat flux (i.e. along the OHP thickness). The evaporator and condenser areas were approximately equal; each accounting for $\sim 25.4 \times 38.1 \mathrm{~mm}^{2}$ (or about half) of the machined face area.

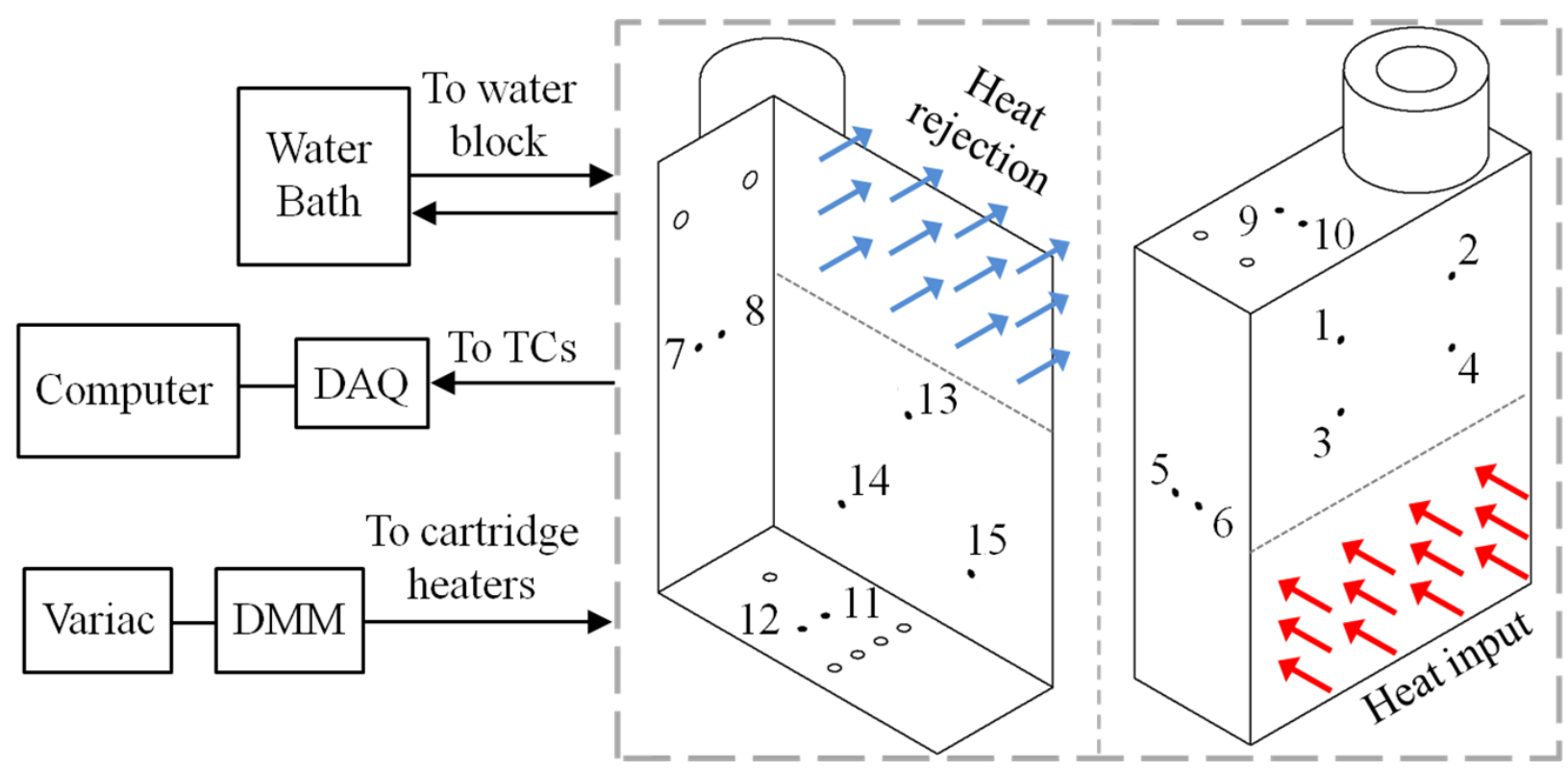

Fig. 3 Experimental setup and thermocouple (TC) locations (black dots) along the bottom-heated ML-OHP surface.

An aluminum water block (with two Ø $10 \mathrm{~mm}$ channels) was tightly clamped to the MLOHP condenser area and connected to a temperature-controlled water bath/circulator (PolyScience AD15R-30-A11B) to allow for an inlet water temperature of approximately $20^{\circ} \mathrm{C}$. An aluminum hot plate - consisting of two embedded $150 \mathrm{~W}$ cartridge heaters (Watlow) - was clamped to the ML-OHP evaporator for achieving near-uniform heat flux conditions. A Variac and digital multimeter (DMM) were utilized for controlling the power supplied to the cartridge heaters. 
Sixteen type-T thermocouples (Omega) were fixed (via Loctite ${ }^{\circledR} 495$ ) on the surface of the MLOHP with locations shown in Fig. 3. Temperature measurements were collected using a data acquisition (DAQ) system (National Instruments cDAQ-9178 chassis with NI-9213 temperature module) connected to a computer equipped with Lab View Signal Express.

Power was supplied to the cartridge heaters in $5 \mathrm{~W}$ increments from 5 to $50 \mathrm{~W}(+/-0.5 \mathrm{~W})$ or until the maximum temperature of the ML-OHP reached $\sim 150{ }^{\circ} \mathrm{C}$. After introducing a new power input, the ML-OHP surface temperature field was allowed to respond until a (pseudo) steady-state was achieved - as evidenced by temperatures oscillating with a time-invariant mean. This steady-state temperature field was recorded for approximately 3 minutes. This process was repeated for each working fluid and orientation investigated (vertical bottom heating and horizontal). The ML-OHP, while filled with each working fluid, was also tested in an 'inverted', vertical top-heating orientation at a power input of approximately $50 \mathrm{~W}$. Thermal paste/epoxy (Omegatherm 201) was applied to condenser and evaporator surfaces, as well as around cartridge heaters, to reduce thermal contact resistance. The ML-OHP, while clamped against the hot plate and water block, was well insulated on all sides while suspended in the rotatable test frame. Heat loss to the environment during testing was found to increase with power input; achieving a maximum of $10 \%$ for a power of $\sim 50 \mathrm{~W}$. The ML-OHP was also tested while empty (and open to atmosphere) for establishing a baseline performance curve.

The average, steady-state temperature difference between the ML-OHP evaporator and condenser, $\Delta T_{\mathrm{avg}}$, was calculated using time-averaged temperature measurements at the $j^{\text {th }}$ location identified in Fig. 3, i.e. $T_{j}$, via Eq. (2):

$$
\Delta T_{\mathrm{avg}}=\left(\frac{T_{11}+T_{12}+T_{14}+T_{15}}{4}\right)-\left(\frac{T_{1}+T_{2}+T_{9}+T_{10}}{4}\right)
$$

These measurement locations were selected to account for temperature gradients along the channel-wise and layer-wise directions in the evaporator and condenser. The temperature difference provided in Eq. (2) was used for defining an effective OHP thermal resistance, $\psi_{\text {eff }}$, for a specific power input, $P$, i.e.:

$$
\psi_{\mathrm{eff}}=\frac{\Delta T_{\mathrm{avg}}}{P}
$$


Since the heat transfer through the OHP is less than the power input, the exact OHP thermal resistance, which is per unit heat transfer, will be higher. The metrics defined in Eqs. (2) - (3) were used for quantifying the thermal performance of the ML-OHP during its operation while using various working fluids (water, acetone, Novec 7200, n-pentane, air/empty), working orientations (vertical bottom-heating, horizontal, vertical top-heating) and power inputs (5-50 W).

To aid discussion regarding the effects of working fluid properties on ML-OHP thermal performance, select dimensionless parameter groups were employed, including the Bond number (Bo), Prandtl number (Pr), inverse Jakob number $\left(\mathrm{Ja}^{-1}\right)$, Galilei number (Ga), and Laplace number (La). Working fluid properties, as summarized in Table 1, were evaluated at a nominal ML-OHP operating temperature of $50^{\circ} \mathrm{C}$, saturation pressure, standard acceleration due to gravity ( $g=9.81$ $\left.\mathrm{m} / \mathrm{s}^{2}\right)$, and a reference temperature difference $\left(\Delta T_{\mathrm{o}}\right)$ of $20{ }^{\circ} \mathrm{C}$. The internal channel surface possessed roughness approximately half of the powder diameter (to be discussed); thus, an effective internal channel radius as $r_{H} \cong 730 \mu \mathrm{m}$, was utilized as the characteristic length. Property values listed in Table 1 were utilized for evaluating the chosen dimensionless groups and their corresponding formulae and magnitudes are summarized in Table 2.

Table 1. Thermophysical and rheological properties of investigated working fluids at $\mathbf{5 0}$ ${ }^{\circ} \mathrm{C}$ and saturation pressure.

\begin{tabular}{cccccccc}
\hline & $\begin{array}{c}\rho_{\mathrm{l}} \\
\left(\mathrm{kg} / \mathrm{m}^{3}\right)\end{array}$ & $\begin{array}{c}\rho_{\mathrm{v}} \\
\left(\mathrm{kg} / \mathrm{m}^{3}\right)\end{array}$ & $\begin{array}{c}\sigma \\
(\mathrm{N} / \mathrm{m})\end{array}$ & $\begin{array}{c}h_{\mathrm{lv}} \\
(\mathrm{kJ} / \mathrm{kg})\end{array}$ & $\begin{array}{c}k_{\mathrm{l}} \\
(\mathrm{W} / \mathrm{m} \cdot \mathrm{K})\end{array}$ & $\begin{array}{c}c_{\mathrm{p}, \mathrm{l}} \\
(\mathrm{kJ} / \mathrm{kg} \cdot \mathrm{K})\end{array}$ & $\begin{array}{c}\mu_{\mathrm{l}} \\
(\mu \mathrm{Pa} \cdot \mathrm{s})\end{array}$ \\
\hline water [52] & 988 & 0.083 & 0.068 & 2382 & 0.644 & 4.19 & 547 \\
Novec 7200 [53,54] & 1365 & 4.47 & 0.011 & 119 & 0.068 & 1.2 & 468 \\
acetone [55,56] & 757 & 1.71 & 0.02 & 525 & 0.172 & 2.25 & 250 \\
n-pentane [52] & 595 & 4.55 & 0.013 & 346 & 0.10 & 2.44 & 177 \\
\hline
\end{tabular}


Table 2. Non-dimensional numbers for investigated working fluids and ML-OHP using property values from Table 1, a characteristic length of $\mathbf{r H}$, standard acceleration due to gravity, $g=9.81 \mathrm{~m} / \mathrm{s}^{2}$, and reference temperature difference $\left(\Delta T_{0}\right)$ of $20^{\circ} \mathrm{C}$.

\begin{tabular}{|c|c|c|c|c|c|}
\hline & $\begin{array}{c}\text { Bond } \\
\text { number }(\text { Bo }) \\
\frac{r_{\mathrm{H}}^{2} g\left(\rho_{\mathrm{l}}-\rho_{\mathrm{v}}\right)}{\sigma}\end{array}$ & $\begin{array}{c}\text { Prandtl } \\
\text { number }(\text { Pr }) \\
\frac{C_{\mathrm{p}, 1} \mu_{1}}{k_{\mathrm{l}}}\end{array}$ & $\begin{array}{l}\text { Inverse Jakob } \\
\text { number }\left(\mathbf{J a}^{-1}\right) \\
\frac{h_{\mathrm{lv}}}{C_{\mathrm{p}, \mathrm{l}} \Delta T_{\mathrm{o}}}\end{array}$ & $\begin{array}{c}\text { Galilei number } \\
\text { (Ga) } \\
\frac{g r_{\mathrm{H}}^{3} \rho_{1}^{2}}{\mu_{1}^{2}}\end{array}$ & $\begin{array}{c}\text { Laplace number } \\
\text { (La) } \\
\frac{\sigma \rho_{1} r_{\mathrm{H}}}{\mu_{1}^{2}}\end{array}$ \\
\hline Water & 0.08 & 3.6 & 28.4 & 12,450 & 163,913 \\
\hline Novec 7200 & 0.65 & 8.3 & 5.0 & 32,465 & 50,045 \\
\hline acetone & 0.20 & 3.3 & 11.7 & 34,990 & 176,835 \\
\hline n-pentane & 0.24 & 4.3 & 7.1 & 43,125 & 180,234 \\
\hline $\begin{array}{l}\text { Bo } \\
\text { Pr } \\
\text { Ja } \\
\text { Ga } \\
\text { La }\end{array}$ & \multicolumn{5}{|c|}{$\begin{array}{l}\text { gravitational forces / surface tension forces } \\
\text { momentum diffusivity / thermal diffusivity } \\
\text { latent energy absorbed / sensible energy absorbed (liquid-vapor phase change at } \Delta \mathrm{T}_{\mathrm{o}} \text { ) } \\
\text { gravitational forces / viscous forces } \\
\text { surface tension / momentum diffusivity }\end{array}$} \\
\hline
\end{tabular}

\section{Experimental Results}

\subsection{Channel surface quality inspection}

Parts fabricated via PBF can have residual, partially-melted particles sintered along their free surfaces within or along the periphery of the part. Although external surfaces of PBF parts can be readily machined for reducing surface roughness, internal surfaces (especially with capillary dimension) are more challenging to post process. Hence, the internal surface quality and topology of the ML-OHP channel structure is worth investigating, as such features can generally impact a fluid's wetting/wicking behavior and heat transfer in an OHP [12,45,46]. For instance, the thin film evaporation, a dominant heat transfer mechanism in the OHP evaporator, as well as the fluid pulsation and convection/condensation, throughout the OHP, depend on the fluid-to-wall wetting behavior (e.g. contact angle, meniscus formation) which depends on surface roughness and condition of the channels. The sensible heat transfer between the evaporator and condenser, accomplished via pulsating advection of the liquid, is also affected by the wall surface roughness as this impacts the channel structure pressure drop, and thus the resulting flow behavior. 
The channel surface quality inside the ML-OHP was first inspected via neutron radiography, which is a unique, non-destructive means for visualizing features within various materials/media. In this method, neutrons are ejected from a neutron source and aimed toward the to-be-inspected materials positioned in front of a camera/detector [47]. The amount of neutrons that pass through or are absorbed by the material depend on the material type, size and density. The High Flux Isotope Reactor (HFIR) CG-1D neutron imaging facilities at Oak Ridge National Laboratory $[48,49]$ were utilized. The ML-OHP was positioned in front of a charge-coupled device (CCD) camera in line with a neutron beam. The detector collected images at a resolution of 100 micron at a rate of $1 \mathrm{fps}$. Radiographs were produced by sampling over a $50 \mathrm{~s}$ time frame. The ML-OHP was inspected as-is; free of any heating or cooling, and its orientation was varied in between runs to obtain frontal and side views of the channel structure. Prior to inspection, the ML-OHP was attached to a vacuum/charging station for removal of its internal working fluid; which was known to be water. Water was also the last working fluid investigated during experimentation. Since the goal of the visualization was to obtain qualitative data, neutron radiographs were only bright field corrected; no special attention was given to volumetric measurements via pixel intensity correlation. The time-averaged (over $50 \mathrm{~s}$ ), contrast-adjusted neutron radiographs of the ML-OHP's front and side are shown in Fig. 4a and Fig. 4b, respectively. Note that the channel structure appears brighter in Fig. $4 \mathrm{~b}$ due to there being less solid material attenuating in that orientation, and the Ti-6Al-4V material appears more transparent (attenuates less) than the residual water due to it possessing less hydrogen. 


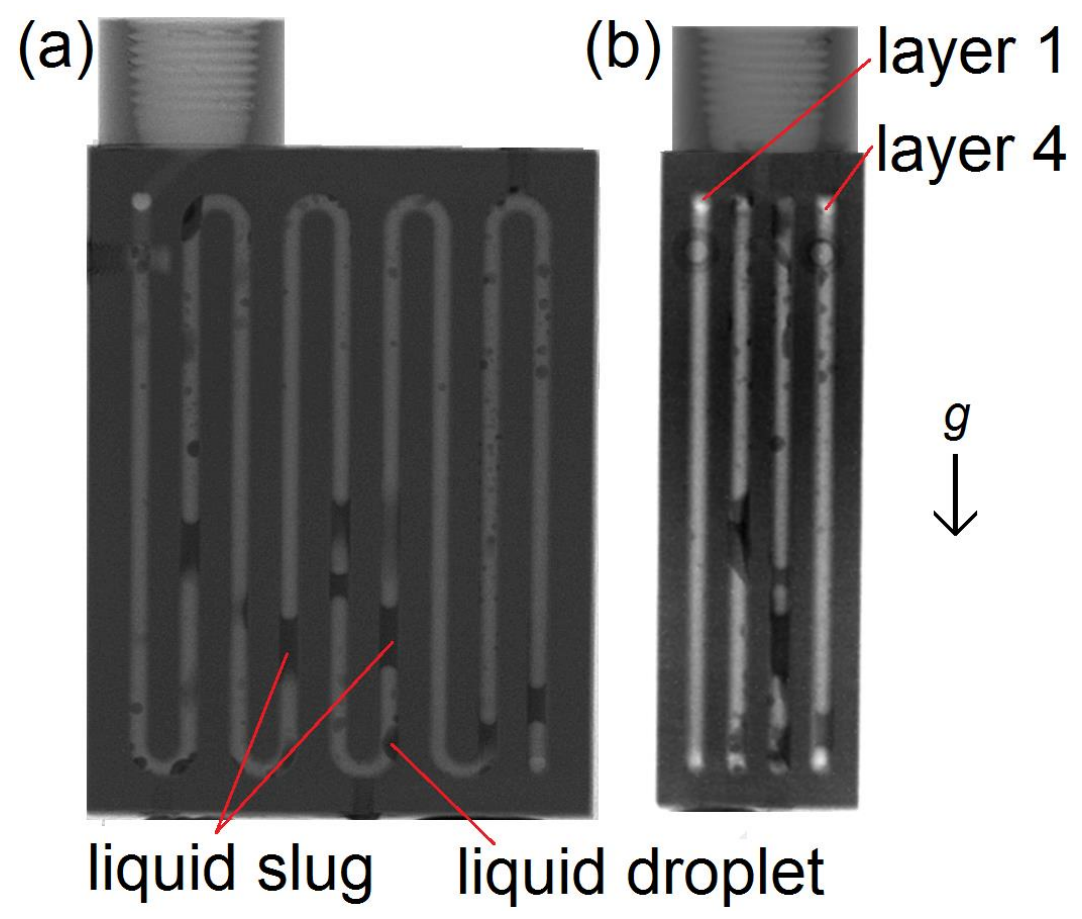

Fig. 4 Neutron radiographs of ML-OHP with residual water slugs and droplets a) front and b) side view

As evidenced in the neutron radiographs shown in Fig. 4, volumes of remnant water existed unevenly along the internal channel structure, despite the preliminary vacuuming procedure. This water most likely remained in the ML-OHP due to its (i) relatively high surface tension and the (ii) notable pressure drop across the entire ML-OHP channel structure. The trapped water slugs exhibit concave menisci indicating secondary wicking along the capillary channel walls. Smaller volumes of residual water, in the form of speckles or droplets, are also observed, further indicating the wicking and adhesive properties of the partially-sintered walls. This is of interest, since previous neutron visualization experiments on liquid wetting behavior in relatively smoother OHP structures $[15-16,33]$ demonstrate full channel wicking with no major evidence of isolated speckles/droplets along walls. Most water slugs/droplets are seen in the lower portions of the MLOHP, indicating the influence of gravity. Figure 4 further indicates that the ML-OHP internal channel structure was clear of any major, solid-phase blockages or other channel obstructions, and this indicates that the OHP was genuinely closed-loop and that the PBF and de-powdering processes were both effective in maintaining channel cross-section continuity. 
Via EDM, a previously-manufactured ML-OHP prototype was sectioned into 1/4 of its original volume by shearing axially along one of its channel layers (i.e. a middle layer), and then along its entire width, to inspect channel surface quality. This specific prototype, although possessing a slightly different design (same internal diameter and number of layers, but different layer orientation), had been designed with insignificant ventilation holes and could not be successfully de-powdered for testing. All channel surfaces were rinsed with acetone prior to inspection. A photograph of the sectioned prototype is provided in Fig. 5.

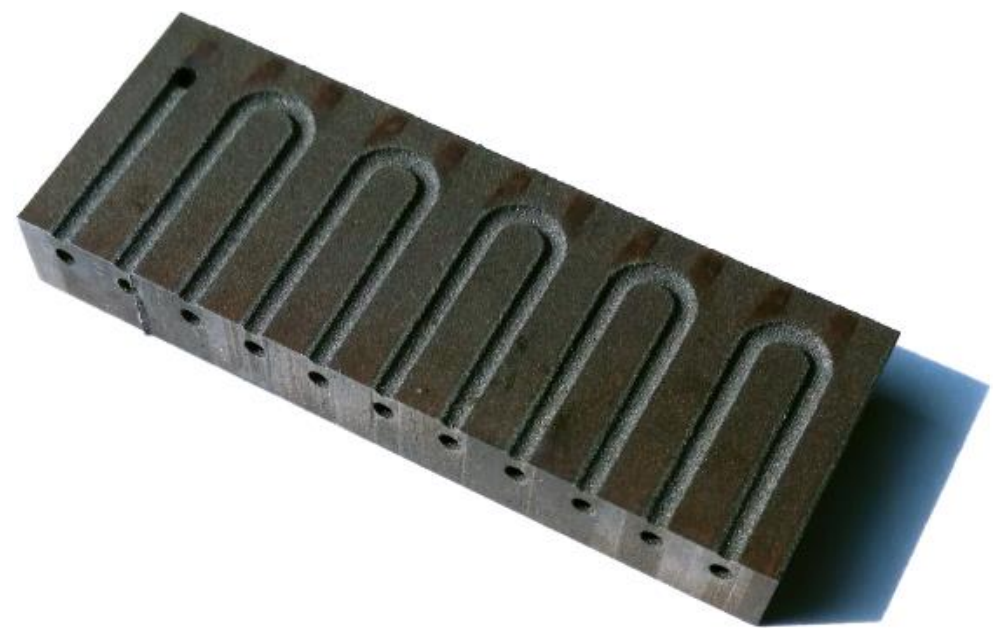

Fig. 5 Photograph of a sectioned Ti-6l-4V ML-OHP prototype used for channel surface characterization.

Portions of the channel structure shown in Fig. 5 were examined using a field emission scanning electron microscope (FESEM). During this process, two high resolution images (each with a different magnification level) of a representative section of the channel structure were obtained and are shown in Fig. 6. The channel roughness is clearly observable in Fig. 6a; especially by comparing it to the EDM'ed surface visible along the top edge of the image. Figure $6 \mathrm{~b}$ better shows the details of the Ti-6Al-4V particles closer to the channel wall and the spherical morphology of the employed powder is confirmed. The majority of sintered particles were found to conform to the manufacturer-specified powder size $(15-45 \mu \mathrm{m})$, although some outliers are evident in Fig. 6b. For the arbitrarily-selected regions of the channel structure inspected via FESEM, no major differences in wall topology was observed and the sections shown in Fig. 6 are deemed representative. 

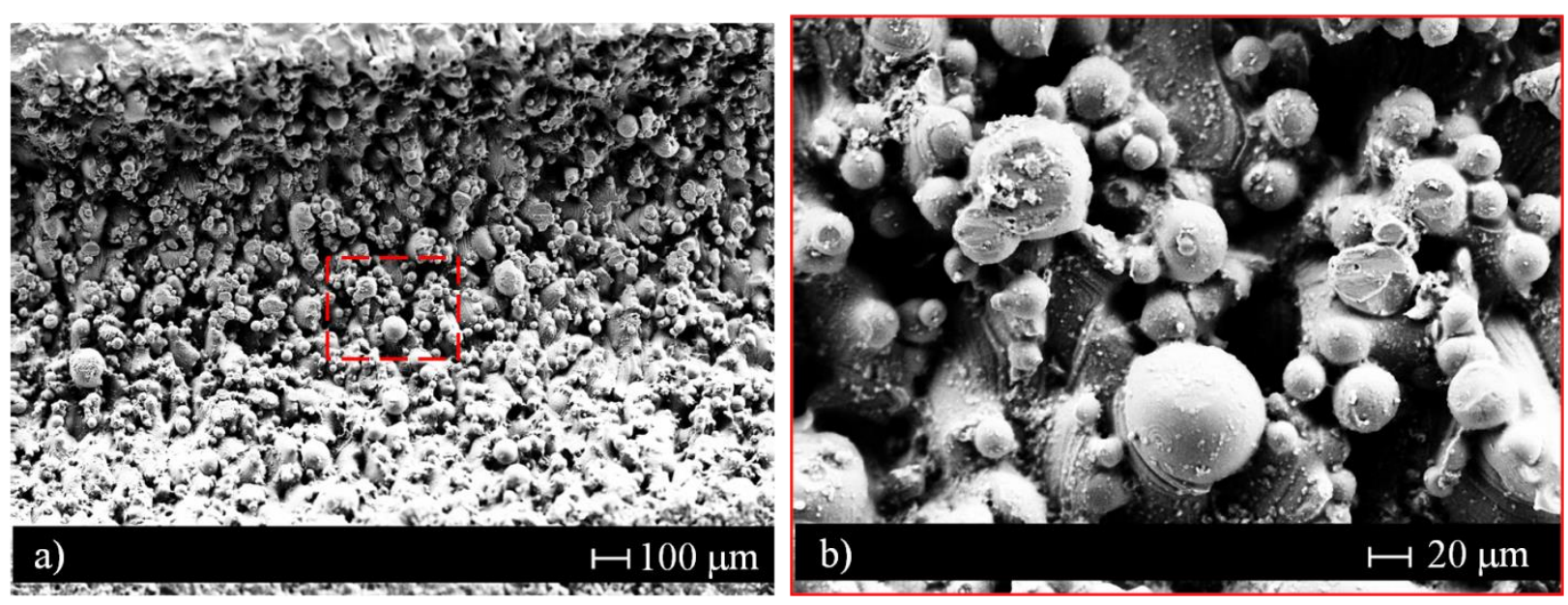

Fig. 6 FESEM images of a channel surface at (a) 54x and (b) 310x magnification

Some of the partially-sintered Ti-6Al-4V particles were found to have surface features themselves. For example, as shown in Fig. 6b, small scars/pits are visible and these may be a result of particle-to-particle abrasion during the de-powdering process. Very small powder debris is also visible around the relatively bigger partially-sintered particles. These smaller particles were found to be either attached to bigger particles, i.e. as satellites, or loose/unrestrained. Such unrestrained particles may actually prove beneficial for increasing heat transfer, as they can suspend into the working fluid and promote micro-to-nanoscale convection enhancements.

Using a high resolution surface profilometer (Taylor-Hobson Talysurf CLI 2000), the surface roughness of the channel structure was inspected within a $0.5 \times 2.5 \mathrm{~mm}^{2}$ frame parallel along the channel floor as shown in Fig. 7. Raw data were adjusted using a least squares method that removed the general curvature of the surface while retaining local surface roughness. From Fig. 7, it may be seen that the surface roughness varied by $\sim 80 \mu \mathrm{m}$ along the channel length (x) for a given transverse (z) location. Surface roughness in excess of $100 \mu \mathrm{m}$ was found to exist along a plane located along half the depth of the circular channel. The resultant topology of the interior channels may depend on the orientation of the channel during its L-PBF manufacture. For example, the relative orientation of the channel length-wise axis and gravity can influence the solidification heat transfer during manufacturing, thus resulting in localized balling phenomena. 


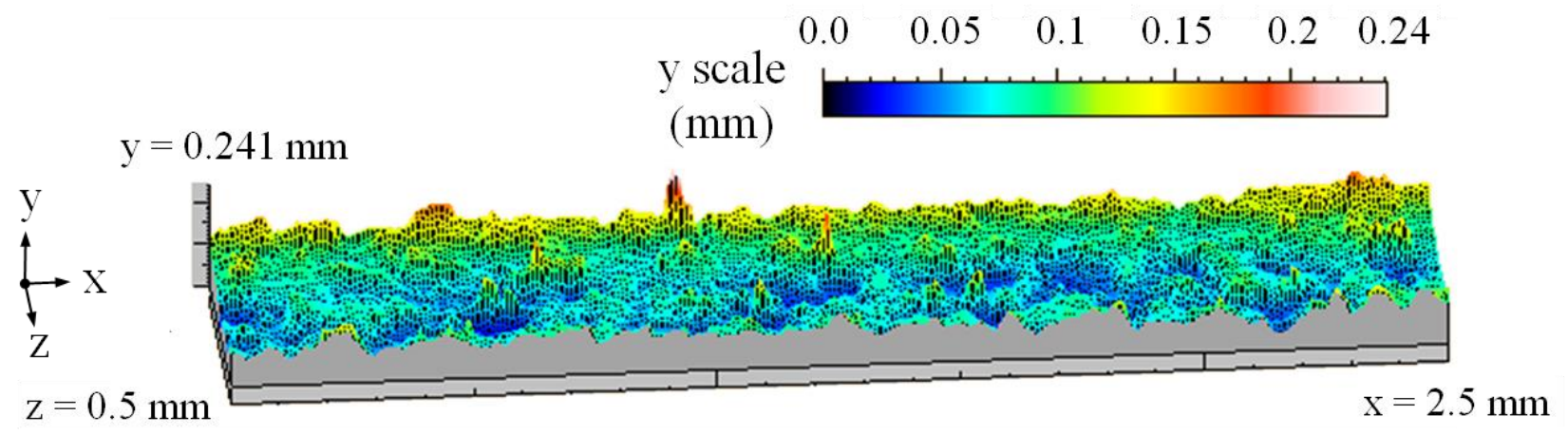

Fig. 7 Topography (surface roughness) of a $0.5 \times 2.5 \mathrm{~mm}^{2}$ section along a representative ML-OHP channel floor.

\subsection{Steady state temperature oscillations}

The Ti-6Al-4V ML-OHP was found to operate successfully for all experimental conditions investigated after a critical power input, which ranged between $10-25 \mathrm{~W}$, was achieved. In most cases, the ML-OHP surface temperature field oscillated, indicating cyclic phase-change heat transfer and fluid pulsation within its channel structure. Representative ML-OHP steady-state temperature oscillations, at the $\mathrm{T}_{14}$ evaporator-side location (see Fig. 3), for a $50 \mathrm{~W}$ power input, and for various orientations and working fluids, are shown in Fig. 8. It may be seen that the steadystate ML-OHP surface temperature oscillated near-consistently with time for all investigated working fluids irrespective of operating orientation. Fluids providing for the highest to lowest evaporator temperature (i.e. $\mathrm{T}_{14}$ measurement) were: acetone, n-pentane, Novec 7200 and water, respectively, and this remained consistent for all operating orientations investigated. These results suggest that fluids with a low product of Ga and La numbers, i.e. $\sim \rho_{L}^{3} / \mu_{L}^{4}$, are desirable for minimizing the evaporator operating temperatures. In general, the average ML-OHP evaporator temperature was found to be relatively insensitive, $\sim 2-3 \%$ change, to operating orientation. The fact that the ML-OHP still functioned while in the top-heating orientation is a significant demonstration of gravity independence as compared to other types of OHPs possessing less channel layers. The enhanced capillarity of the internal channel structure, due to the peripheral, secondary wicking structure consisting of partially-sintered particles, provides a means to increase liquid pumping from the condenser to the evaporator. The partially melted powder can increase the capillary pressure inside the OHP, thus reducing gravity effects on fluid flow. 

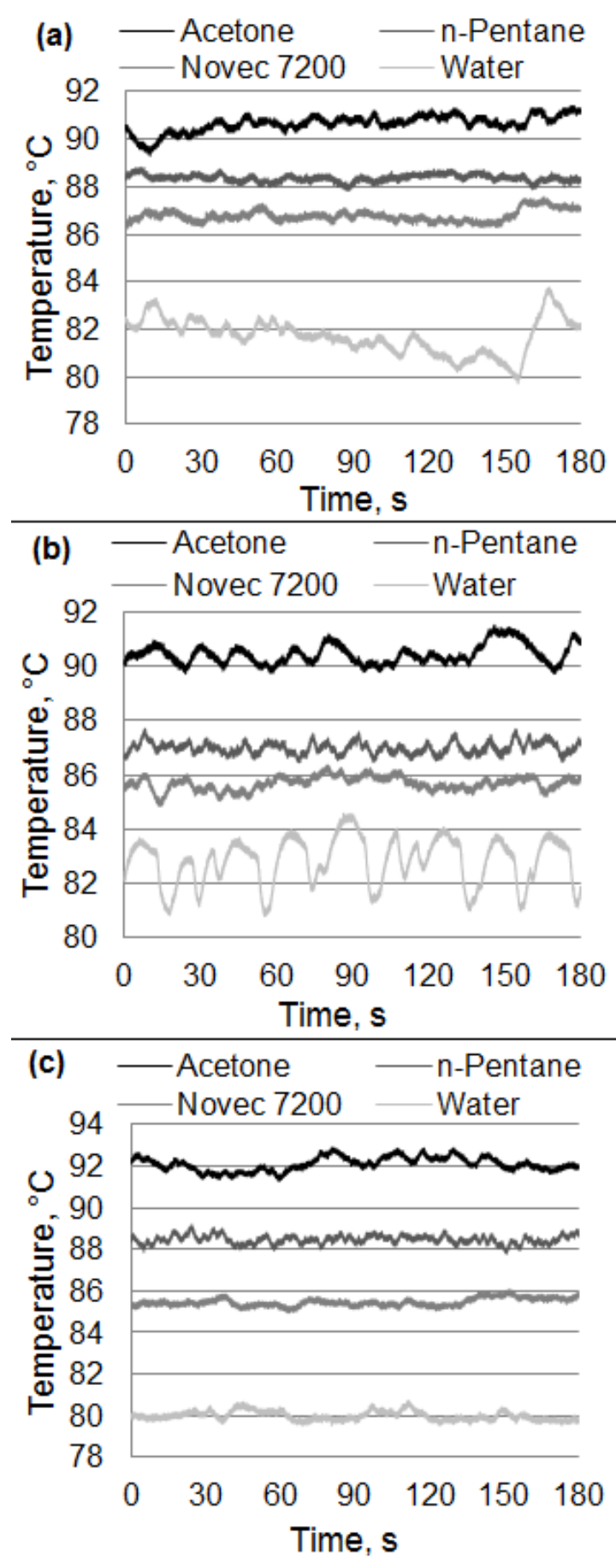

Fig. 8 Local steady-state ML-OHP surface temperature (T14) vs. time while filled with either acetone, $n$-pentane, water, or Novec 7200 and operating at $P \cong 50 \mathrm{~W}$ for the following heating modes: (a) vertical bottom-heating, (b) vertical top-heating, (c) horizontal. 
Although the average $\mathrm{T}_{14}$ evaporator temperature remained near constant, the apparent amplitude and frequency of $\mathrm{T}_{14}$ were found to depend on the working fluid and the ML-OHP operating orientation. Evaporator temperatures slightly increased for all working fluids in the horizontal orientation, except for water and Novec 7200, which decreased and remained unchanged, respectively. The water ML-OHP was most sensitive to operating orientation, as its $\mathrm{T}_{14}$ temperature oscillations changed significantly in both frequency and amplitude for different working orientations. Water temperature oscillations possessed higher apparent frequency while the ML-OHP operated during bottom-heating relative to horizontal and top-heating orientations. Going from vertical bottom-heating to vertical top-heating resulted in the water ML-OHP evaporator temperature field to pulsate at higher amplitude and frequency. This trend was also observed for the other working fluids, but not to the same extent as water. In the horizontal heating mode, the evaporator temperature of the water ML-OHP became more stable, indicating its strong coupling with gravity.

Non-dimensional parameter groups are useful for describing working fluid wetting behavior, capillarity, heat transfer ability, rheology and more. Results suggest that a fluid's Ga number is indicative of its fluid pulsation behavior with respect to gravity. Water, having the lowest Ga and Bo numbers of the group, was highly sensitive to operating orientation, while npentane, having the highest Ga number of the group, provided for temperature oscillations nearindependent of operating orientation. Working fluids with a high inverted Ja number were observed to provide for higher temperature amplitudes at lower frequency. This is especially evidenced by the water and acetone temperature oscillations during vertical top-heating of the MLOHP. Based on these observations, it appears that the working fluid's latent heat of vaporization affects OHP surface temperature oscillation and frequency while also making the OHP more sensitive to operating orientation. Both Novec 7200 and n-pentane have the highest Bo number and appear to provide for the most consistent temperature oscillations irrespective of operating orientation. Acetone and n-pentane have similar temperature oscillations during the horizontal operating mode, and they both share a high La number - indicating the importance of viscosity and surface tension in the absence of direct gravity influence. Both Novec 7200 and n-pentane ML-OHPs had local evaporator temperatures decrease when going from bottom-heating to topheating orientations, although their thermal resistances increases. It is interesting to note that both of these fluids possess relatively dense vapor and low inverted Ja numbers. 
The surface temperature field measured along the ML-OHP was inspected to determine the effect of multiple channel layers on the evaporator-to-condenser heat transfer. The steady-state temperature oscillations as recorded at locations $T_{1}-T_{15}$ for the bottom-heated acetone and water ML-OHPs, at $\sim 40 \mathrm{~W}$ power input, are provided in Fig. 9-10. Based on the thermocouple arrangement set forth herein (as shown in Fig. 3), four regions are of concern, including the layer immediately underneath the heat source, i.e. the primary 'evaporator layer', the layer in contact with the heat sink, i.e. the primary 'condenser layer', one of the adiabatic sides of the ML-OHP, as well as the opposite heated/cooled ends of the ML-OHP. In general, the water ML-OHP surface temperature field was substantially more 'active' for all locations measured, suggesting that low Bo and Ga numbers are important in establishing spatially-uniform fluid pulsation with respect to ML-OHP channel layer and region. Such uniform, and strong, surface pulsations were only observed for the water ML-OHP. All other ML-OHPs demonstrated strong temperature oscillations near the evaporator, but less active oscillations along the ML-OHP sides and near the condenser. Assuming temperature amplitudes are related to latent heat transfer, as the current results suggest; then clearly the high inverse Jakob number of water allows for more severe temperature amplitudes measured along the outer ML-OHP structure. Results indicate that working fluids with lower Pr numbers provide for temperature oscillations of more similar magnitude between the evaporator- and condenser-side regions. For the case of Novec 7200, which has the highest Pr number, the phase-change heat transfer in the condenser is shown to be most likely less than that occurring in the evaporator. 

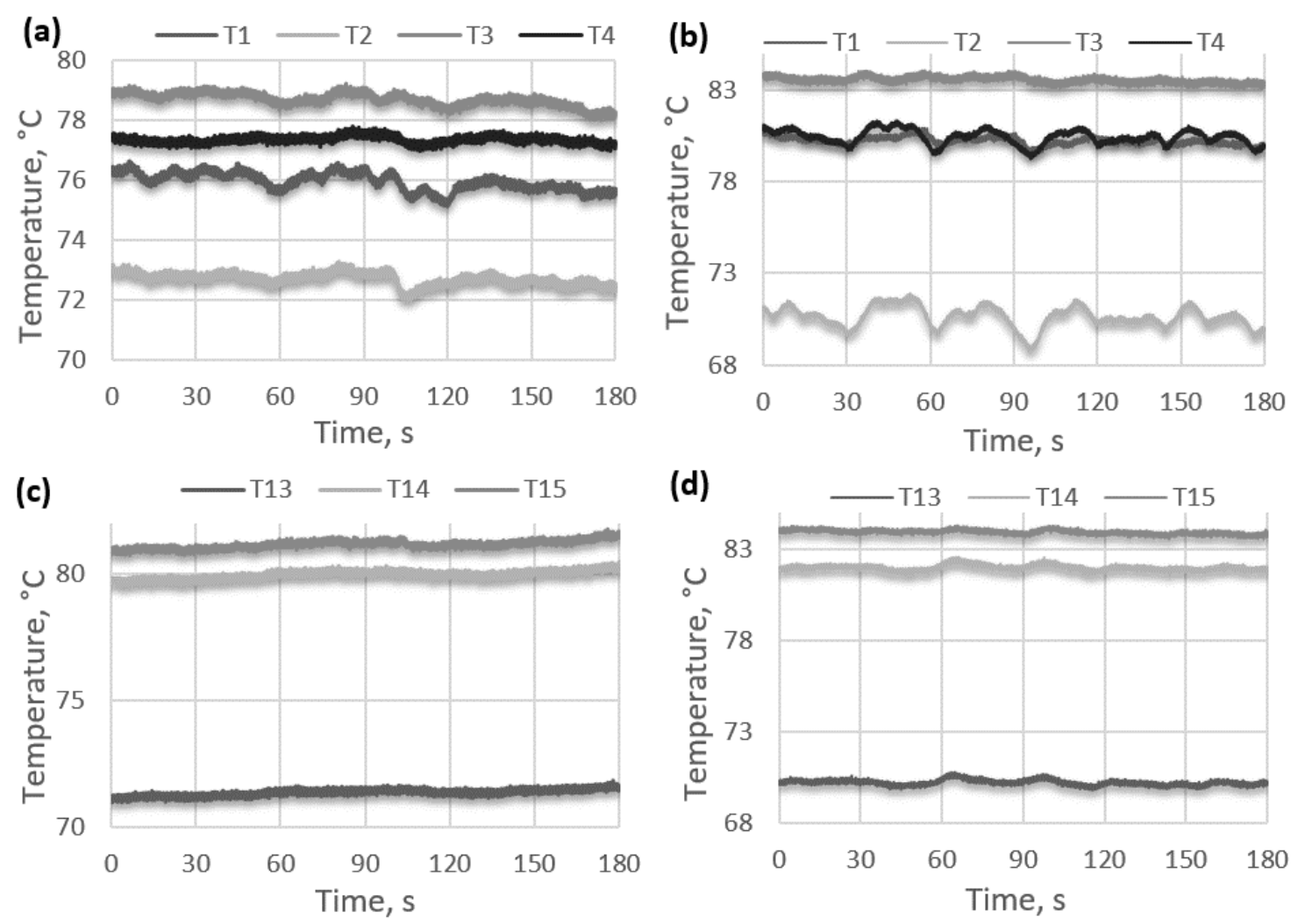

Fig. 9 Local steady-state ML-OHP surface temperature vs. time at $P \cong 40 \mathrm{~W}$ for vertical bottom-heating: (a) acetone 'evaporator layer' T1 - T4, (b) water 'evaporator layer' $\mathrm{T} 1$ - T4, (c) acetone 'condenser layer' $\mathrm{T} 13$ - T15, (d) water 'condenser layer' T13 - T15. 

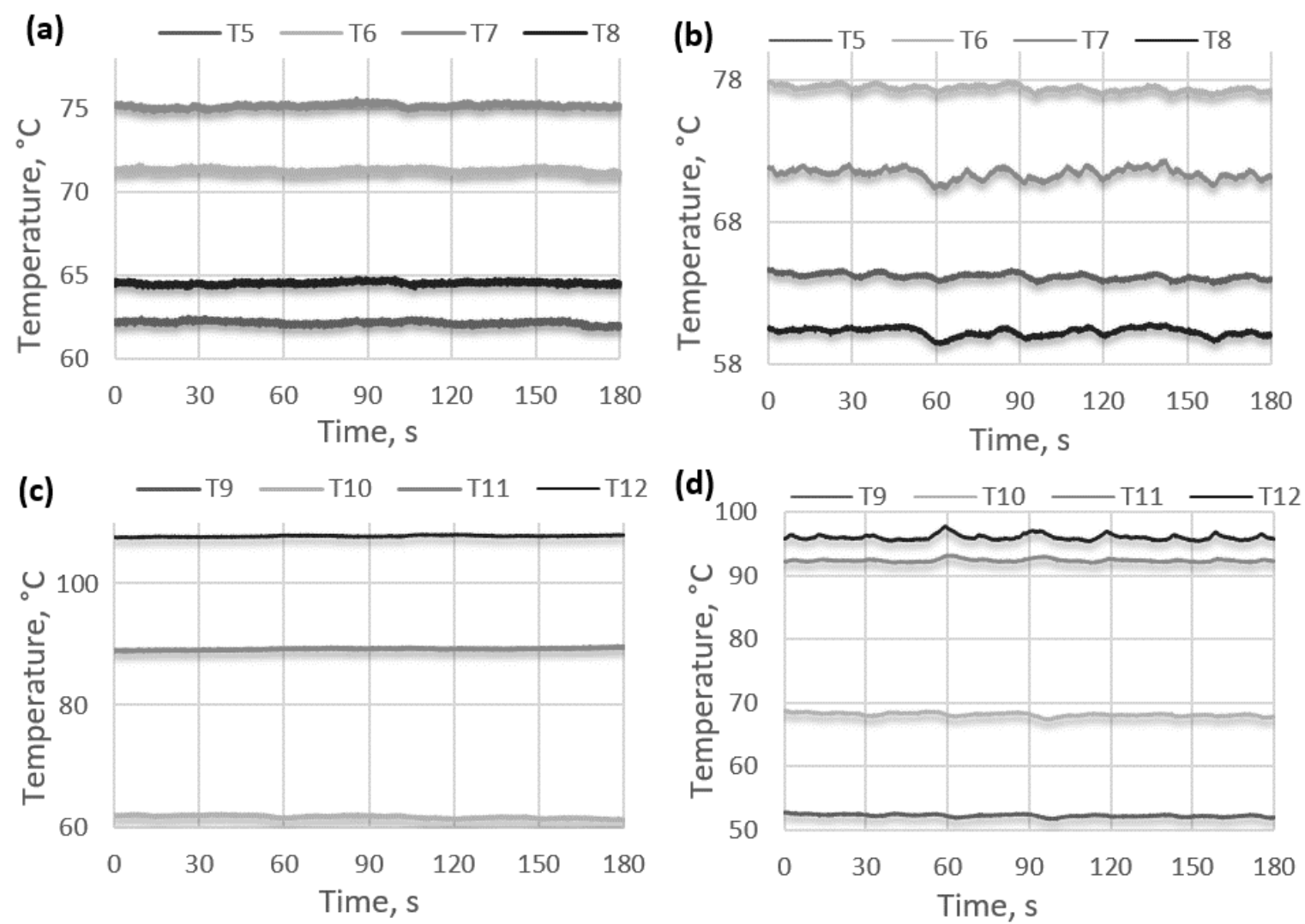

Fig. 10. Local steady-state ML-OHP surface temperature vs. time at $P \cong 40 \mathrm{~W}$ for vertical bottom-heating: (a) acetone 'adiabatic side' T5 - T8, (b) water 'adiabatic side' $\mathrm{T} 5$ - T8, (c) acetone evaporator $\mathrm{T} 11$ - $\mathrm{T} 12$ and condenser $\mathrm{T} 9$ - T10 ends, (d) water evaporator T11 - T12 and condenser T9 - T10 ends.

The multi-layer design feature of the ML-OHP allows for higher channel-to-volume density and thus more high heat flux mitigation. Even for the current prototype, in which the channel layer-to-layer (and even adjacent channel-to-channel) distance was not minimized, the evaporator-to-condenser heat flux was found to provide sufficient vapor pressure for fluid pulsation within each of the OHP's four layers; regardless of working fluid used. It is clear that the ML-OHP designer should consider the depth of heat penetration from the heat source, as this will establish the number of heat affected layers capable of producing vapor. Depending on the heat penetration depth and the heating/cooling configuration, each heat affected layer may behave as an independent OHP. Hence, in order to design the ML-OHP for a given application, it is best to consider the container thermal conductivity, as well as the thermal spreading/constriction resistance, to best estimate the level of heat penetration and number of heat affected layers. 


\subsection{Effective thermal resistance}

The effective thermal resistance of the ML-OHP for multiple power inputs, during the vertical bottom-heating and horizontal orientations, for all working fluids investigated, is shown in Fig. 11. It may be seen that the ML-OHP's effective thermal resistance generally decreases as power input increases and that it depends on the working fluid type, operating orientation and power input. The ML-OHP effective thermal resistance, while in the vertical bottom-heating orientation, was found to be lower than that while in the horizontal orientation for most working fluids - demonstrating that the four-layered, closed loop capillary structure is still somewhat gravity dependent. In all cases, the top heating mode proved most detrimental to OHP thermal performance. This was expected, since in these cases the capillary force direction of evaporatorbound condensate is opposite of that for liquid weight. The ML-OHP, while filled with n-pentane or Novec 7200 and operating in the horizontal orientation, started to function near $10 \mathrm{~W}$ of power input; and this is $\sim 150 \%$ lower than that required for water $(\sim 25 \mathrm{~W})$ due to its relatively lower viscosity and La number. This also suggests that fluids with relatively high inverted Ja numbers require more heat transfer to initiate their oscillation within an OHP. The acetone ML-OHP in the vertical/bottom-heating orientation had the lowest thermal resistance, and this may be attributed to the low viscosity and La number of acetone. However, although the effective thermal resistance of the acetone ML-OHP was low, its maximum evaporator temperature was the highest of all fluids investigated as shown in Fig. 8. The relatively long internal channel structure of the ML-OHP can possess a high pressure drop, and fluids with relatively lower viscosity may be more advantageous for reducing overall thermal resistance. 


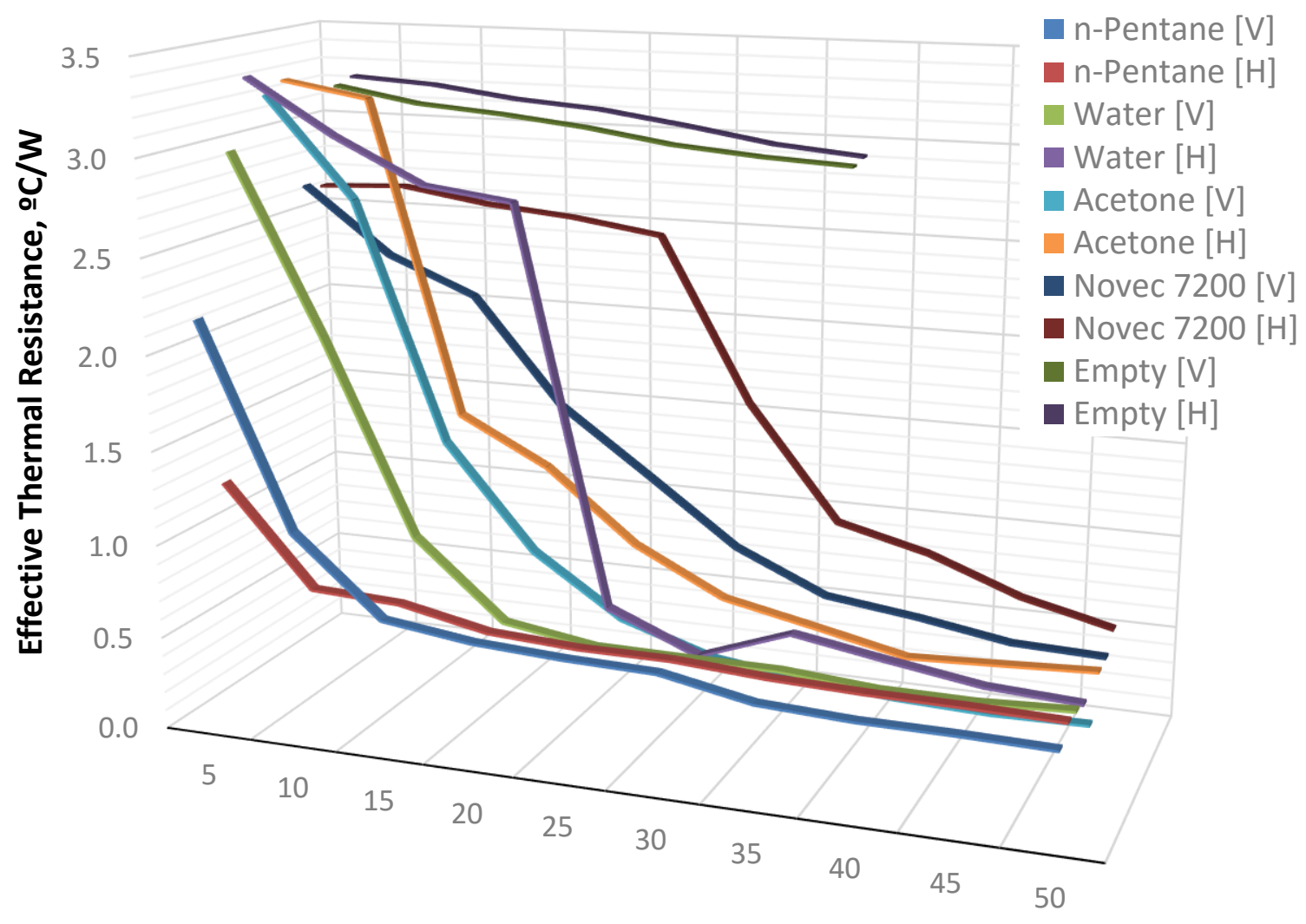

Power, W

Fig. 11. Effective ML-OHP thermal resistance vs. power input while filled with either $\mathbf{n}$ pentane, water, acetone, Novec 7200 or while empty (control group) in either the vertical (V) or horizontal (H) operating orientation.

As expected, the empty ML-OHP provides for the maximum thermal resistance for all orientations investigated. Relative to the empty ML-OHP, the acetone ML-OHP provides for an $85 \%$ lower effective thermal resistance. Without a working fluid to aid thermal transport via phase change and physical oscillations, conduction through the Ti-6Al-4V ML-OHP (a metal with a relatively low thermal conductivity: $6.7 \mathrm{~W} / \mathrm{m} \cdot \mathrm{K}$ ) is the only available mode for heat transfer. As shown in Fig. 12, all ML-OHPs investigated tend to have an effective thermal resistance that increases going from bottom-heating, to horizontal-heating, then to top-heating. The exception is the water ML-OHP, which performed best while in the horizontal orientation. This indicates that water's unique rheological and inertial properties (providing for relatively low $\mathrm{Ga}$ and Bo numbers), combined with the ML-OHP design, provides for a more gravity-dependent ML-OHP. The density of water vapor is also significantly lower than those of the other investigated working 
fluids and this may also play a role. Water does provide for the lowest effective thermal resistance relative to other fluids while the ML-OHP is in the horizontal orientation; indicating that a low Ja number may be advantageous for optimal OHP operation in absence of a collinear gravity force vector. The results indicate that low La numbers, or high Bo and Pr numbers, may correlate to lower OHP heat transfer ability, as well. This is supported by observing that Novec 7200, which provided for the lowest La, and highest Bo and $\mathrm{Pr}$, for the investigated ML-OHP, resulted in the highest recorded effective thermal resistance for all orientations investigated.

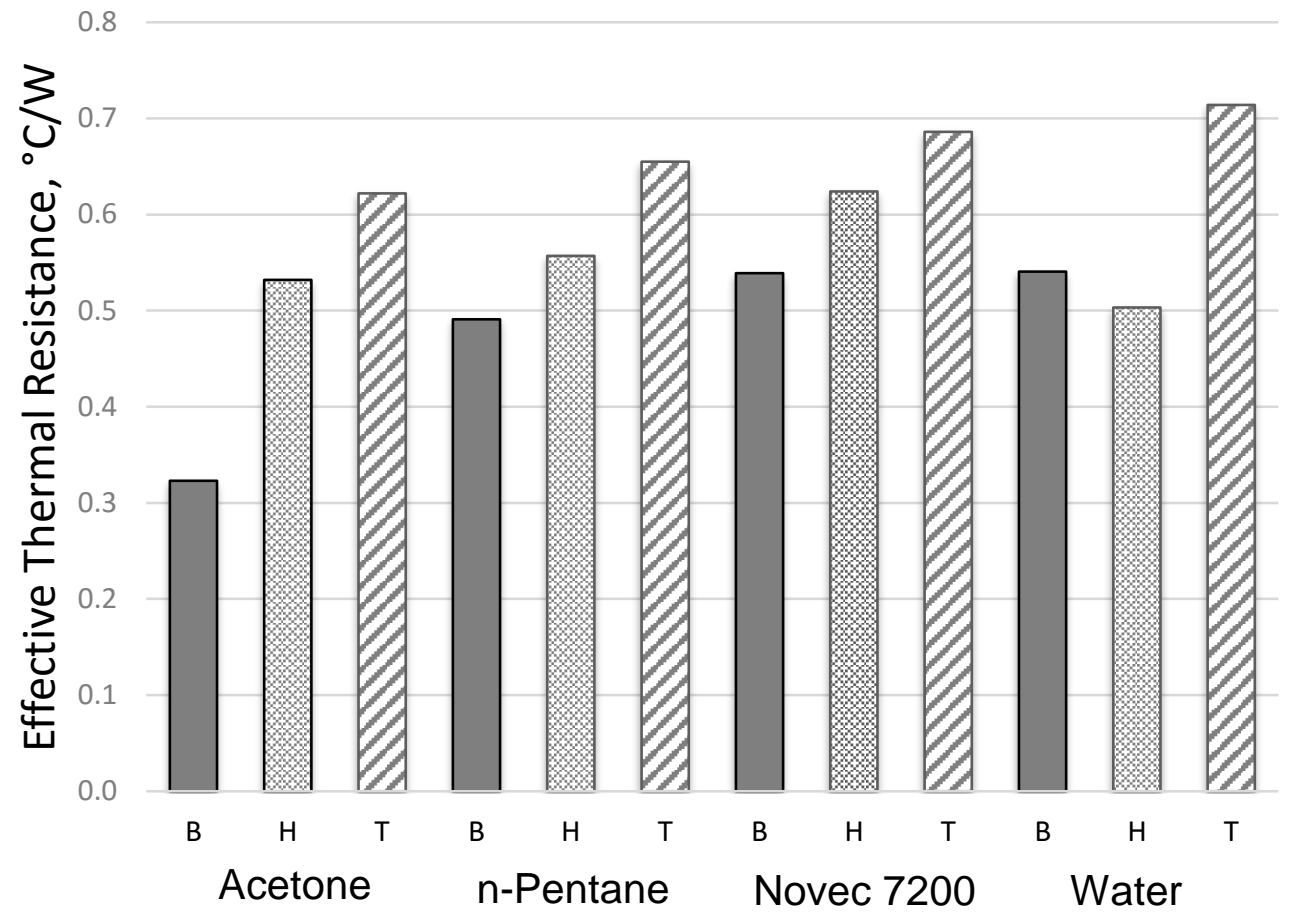

Fig. 12 Average, effective thermal resistance of ML-OHP while operating at $P=50 \mathrm{~W}$ for three different orientations: vertical bottom-heating, 'B', horizontal, ' $H$ ', vertical/top-heating, ' $T$ ') and various working fluids (water, acetone, $n$-pentane, Novec 7200).

\section{Conclusions}

A Ti-6Al-4V multi-layered oscillating heat pipe (ML-OHP) was successfully fabricated using laser powder bed fusion (L-PBF) additive manufacturing. The device consisted of four interconnected layers of circular mini-channels which were successfully de-powdered after L-PBF. The ML-OHP was experimentally investigated in either the bottom-heating, top-heating, or 
horizontal orientations, while being partially filled with either Novec 7200, acetone, n-pentane or water. The ML-OHP was heated and cooled on opposing planes and sides to determine heat transfer ability of the stacked layers. The heat pipe was characterized for surface quality, fluid wicking behavior and thermal performance, and some of the major results are summarized below.

1) Working fluid within the ML-OHP displays unique wicking behavior; due partially to residual, sintered powder along the periphery of the OHP channel. The characteristic surface roughness was found to be almost twice the maximum diameter of the spherical Ti-6Al-4V powder used for manufacture. These features should increase the capillary pumping ability of the OHP and promote boiling heat transfer during start-up, resulting in reduced gravity dependence and a reduced OHP start-up power requirement, respectively.

2) No solid blockages were found within the channel structure, demonstrating the utility of LPBF for fabricating mini-channel devices. A means for de-powdering the internal channel structure must be integrated at the design phase.

3) The ML-OHP, which consisted of four interconnected channel layers, was shown to operate effectively while filled with water, Novec 7200, acetone or n-pentane, almost independent of operating orientation. This demonstrates that the OHP is 'stackable' when embedded in solid media.

4) The vertically-bottom-heated, acetone ML-OHP and the horizontal-oriented, water ML-OHP each possessed the lowest thermal resistances measured. Working fluids, like n-pentane and Novec 7200, started oscillating at relatively low heat inputs while others, like water, started oscillating at much higher heat inputs. Novec 7200 provided for the highest effective thermal resistance in all orientations.

5) The ML-OHP evaporator size depends on the number of heat affected layers underneath the heat source and the heating/cooling configuration. Thus, the heat penetration depth resulting from the heat source is of importance, and the thermal spreading resistance of the evaporator and container material should be considered during design.

6) The apparent amplitude and frequency of temperature oscillations were found to depend on working fluid and the ML-OHP operating orientation. The water ML-OHP temperature oscillations were most sensitive, in frequency and amplitude, to operating orientation. The water ML-OHP surface temperature field was the most spatially uniform. 
Results suggest important trends in non-dimensional numbers, OHP effectiveness and working condtions. Working fluids with low Bond and Prandtl numbers may be more advantageous for effective OHP operation, while higher inverted Jakob numbers appear to correspond to an OHP with larger temperature amplitudes along its external surface. OHPs that employ working fluids with relatively low Galilei numbers may be more prone to adverse gravitational effects, while low Laplace numbers, in the absence of major gravity influence, may be indicative of reduced OHP thermal performance. Fluids with a low Ga x La product may be desirable for minimizing the operating temperature of the OHP.

There are many potential benefits for using emerging AM technology for fabricating stateof-the-art heat transfer devices, especially those with embedded channel structures. Methods such as laser-powder bed fusion (L-PBF), are especially beneficial in allowing one to build channel structures with complex cross-sections and arrangements, due to the powder bed serving as an inadvertent support structure during the layer-by-layer manufacturing process. Many metallic powders are available for the thermal engineer to design conformal heat transfer media. For instance, and as demonstrated in this study, one can use Ti-6Al-4V, which has a desirable coefficient of thermal expansion (CTE), for building heat transfer media in intimate contact with silicon-based, heat dissipating sources. The thermal engineer is now challenged with the unique task of 're-designing the wheel'; as once-impossible design concepts are now feasible for manufacture. Since thermal media typically do not experience high mechanical loads during operation, there is less hesitation in introducing additive-manufactured heat exchangers to various applications.

The benefit/cost of having PBF-sourced, partially-sintered channel structures within an OHP, or any other heat transfer device, will depend on its operating conditions/application. For the case of OHPs, the roughened surfaces can decrease the start-up power threshold of the OHP (due to boiling enhancements and secondary capillary action) while decreasing its power limit (since pressure balancing within the evaporator becomes easier to obtain during operation) $[12,46,50,51]$. However, if these characteristics were not needed or even undesirable for a certain application, methods such as purging the channels with an acidic solution to etch the sintered particles could be an option for reducing channel roughness. Residual powder not attached to channel could prove advantageous for OHP operation, as low-concentration, micro/nano-fluid suspensions can form due to mixing from consistent fluid pulsation along the channel structure. 


\section{Acknowledgments}

This work was sponsored in-part by the National Science Foundation (CBET-1403872 \& ECCS 1660446). A portion of this research employed resources at the High Flux Isotope, a DOE Office of Science User Facility operated by the Oak Ridge National Laboratory (ORNL). Portions of this manuscript were prepared while Drs. Scott Thompson and Nima Shamsaei were Assistant Professors at Mississippi State University (MSU).

\section{References}

[1] G.E. Moore, Cramming More Components onto Integrated Circuits, Electronics. (1965) 114-117.

[2] A. Bar-Cohen, J.J. Maurer, J.G. Felbinger, DARPA's Intra/Interchip Enhanced Cooling (ICECool) Program, CS MANTECH Conf. (2013) 171-174. http://www.csmantech.org/Digests/2013/papers/050.pdf.

[3] A. Bar-Cohen, K. Matin, N. Jankowski, D. Sharar, Two-Phase Thermal Ground Planes: Technology Development and Parametric Results, ASME J. Electron. Packag. 137 (2015) 10801. doi:10.1115/1.4028890.

[4] C.H. Zweben, Advances in High-Performance Thermal Management Materials - A Review, J. Adv. Mater. 39 (2007) 3-10.

[5] F.F. Laun, H. Lu, H.B. Ma, An Experimental Investigation of an Oscillating Heat Pipe Heat Spreader, ASME J. Therm. Sci. Eng. Appl. 7 (2015) 21005. doi:10.1115/1.4026815.

[6] M. Sigurdson, Y. Liu, P. Bozorgi, D. Bothman, N. MacDonald, C. Meinhart, A large scale Titanium Thermal Ground Plane, Int. J. Heat Mass Transf. 62 (2013) 178-183. doi:10.1016/j.ijheatmasstransfer.2013.01.064.

[7] S.M.. Thompson, H.B. Ma, Recent Advances in Two-Phase Thermal Ground Planes, Annu. Rev. Heat Transf. 18 (2015). doi:10.1615/AnnualRevHeatTransfer.2015011163.

[8] S.M. Thompson, H. Lu, H. Ma, Thermal Spreading with Flat-Plate Oscillating Heat Pipes, J. Thermophys. Heat Transf. 29 (2015) 338-345. doi:10.2514/1.T4168.

[9] Q. Cai, B. Chen, C. Tsai, Design, development and tests of high-performance silicon vapor chamber, J. Micromechanics Microengineering. 22 (2012) 35009. doi:10.1088/09601317/22/3/035009.

[10] P. Naphon, S. Wongwises, S. Wiriyasart, On the thermal cooling of central processing unit of the PCs with vapor chamber, Int. Commun. Heat Mass Transf. 39 (2012) 1165-1168. doi:10.1016/j.icheatmasstransfer.2012.07.013.

[11] J.B. Boreyko, C.H. Chen, Vapor chambers with jumping-drop liquid return from superhydrophobic condensers, Int. J. Heat Mass Transf. 61 (2013) 409-418. doi:10.1016/j.ijheatmasstransfer.2013.01.077.

[12] C.D. Smoot, H.B. Ma, an Experimental Investigation of Hybrid Oscillating Heat Pipe, Front. Heat Pipes. 2 (2011) 1-6. doi:10.5098/fhp.v2.2.3001. 
[13] H. Ma, Oscillating Heat Pipes, 1st ed., Springer-Verlag New York, New York, 2015. doi:10.1007/978-1-4939-2504-9.

[14] H. Akachi, F. Polasek, P. Stulc, Pulsating Heat Pipes, in: Proc. 5th Int. Heat Pipe Symp., Melbourne, Australia, 1996: pp. 208-217.

[15] C. Wilson, B. Borgmeyer, R. a. Winholtz, H.B. Ma, D.L. Jacobson, D.S. Hussey, M. Arif, Visual Observation of Oscillating Heat Pipes Using Neutron Radiography, J. Thermophys. Heat Transf. 22 (2008) 366-372. doi:10.2514/1.33758.

[16] I. Yoon, C. Wilson, B. Borgmeyer, R.A. Winholtz, H.B. Ma, D.L. Jacobson, D.S. Hussey, Neutron phase volumetry and temperature observations in an oscillating heat pipe, Int. J. Therm. Sci. 60 (2012) 52-60. doi:10.1016/j.ijthermalsci.2012.05.004.

[17] S.M. Thompson, A.A. Hathaway, C.D. Smoot, C.A. Wilson, H.B. Ma, R.M. Young, L. Greenberg, B.R. Osick, S. Van Campen, B.C. Morgan, D. Sharar, N. Jankowski, Robust Thermal Performance of a Flat-Plate Oscillating Heat Pipe During High-Gravity Loading, J. Heat Transfer. 133 (2011) 104504. doi:10.1115/1.4004076.

[18] Y. Zhang, A. Faghri, Advances and Unsolved Issues in Pulsating Heat Pipes, Heat Transf. Eng. 29 (2008) 20-44. doi:10.1080/01457630701677114.

[19] J. Gu, M. Kawaji, R. Futamata, Microgravity performance of micro pulsating heat pipes, Microgravity - Sci. Technol. 16 (2005) 181-185. doi:10.1007/BF02945972.

[20] P. Cheng, J. Dong, S.M. Thompson, H.B. Ma, Heat transfer in the bulk and thin film fluid regions of a rectangular micro groove, J. Thermophys. Heat Transf. 26 (2012) 108-114. doi:10.2514/1.T3684.

[21] W. Qu, H.B. Ma, Theoretical analysis of startup of a pulsating heat pipe, Int. J. Heat Mass Transf. 50 (2007) 2309-2316. doi:10.1016/j.jiheatmasstransfer.2006.10.043.

[22] P. Charoensawan, S. Khandekar, M. Groll, P. Terdtoon, Closed loop pulsating heat pipes Part A: Parametric experimental investigations, Appl. Therm. Eng. 23 (2003) 2009-2020. doi:10.1016/S1359-4311(03)00159-5.

[23] M.B. Shafii, M.B. Shafii, a. Faghri, a. Faghri, Y. Zhang, Y. Zhang, Analysis of heat transfer in unlooped and looped pulsating heat pipes, Int. J. Numer. Methods Heat Fluid Flow. 12 (2002) 585-609. doi:10.1108/09615530210434304.

[24] B.S. Taft, A.D. Williams, B.L. Drolen, Review of Pulsating Heat Pipe Working Fluid Selection, J. Thermophys. Heat Transf. 26 (2012) 651-656.

[25] J. Gu, M. Kawaji, R. Futamata, Effects of Gravity on the Performance of Pulsating Heat Pipes, AIAA J. Thermophys. Heat Transf. (2004).

[26] S. Khandekar, Thermofluid Dynamic Study of Flat-Plate Closed-Loop Pulsating Heat Pipes, Microscale Thermophys. Eng. 6 (2003) 303-317. doi:10.1080/10893950290098340.

[27] B. Borgmeyer, H. Ma, Experimental Investigation of Oscillating Motions in a Flat Plate Pulsating Heat Pipe, J. Thermophys. Heat Transf. 21 (2007) 405-409. doi:10.2514/1.23263.

[28] D. Mangini, M. Mameli, A. Georgoulas, L. Araneo, S. Filippeschi, M. Marengo, A pulsating heat pipe for space applications: Ground and microgravity experiments, Int. J. Therm. Sci. 95 (2015) 53-63. doi:10.1016/j.ijthermalsci.2015.04.001.

[29] B.S. Taft, F.F. Laun, S.M. Smith, D.W. Hengeveld, Microgravity Performance of a 
Structurally Embedded Oscillating Heat Pipe, AIAA J. Thermophys. Heat Transf. 29 (2015) 329-337. doi:10.2514/1.T4151.

[30] J. Van Es, A.A. Woering, High-acceleration performance of the Flat Swinging Heat Pipe High-acceleration performance of the Flat Swinging Heat Pipe, (2000).

[31] R.R. Riehl, Characteristics of an open loop pulsating heat pipe, SAE Tech. Pap. (2004). doi:10.4271/2004-01-2509.

[32] S.M. Thompson, P. Cheng, H.B. Ma, An experimental investigation of a three-dimensional flat-plate oscillating heat pipe with staggered microchannels, Int. J. Heat Mass Transf. 54 (2011) 3951-3959. doi:10.1016/j.ijheatmasstransfer.2011.04.030.

[33] S.M. Thompson, H.B. Ma, R. a. Winholtz, C. Wilson, Experimental Investigation of Miniature Three-Dimensional Flat-Plate Oscillating Heat Pipe, J. Heat Transfer. 131 (2009) 43210. doi:10.1115/1.3072953.

[34] C.D. Smoot, H.B. Ma, Experimental Investigation of a Three-Layer Oscillating Heat Pipe, J. Heat Transfer. 136 (2014) 51501. doi:10.1115/1.4026217.

[35] B. Borgmeyer, C. Wilson, R. a. Winholtz, H.B. Ma, D. Jacobson, D. Hussey, Heat Transport Capability and Fluid Flow Neutron Radiography of Three-Dimensional Oscillating Heat Pipes, J. Heat Transfer. 132 (2010) 61502. doi:10.1115/1.4000750.

[36] B.S. Taft, Non-Condensable Gases and Oscillating Heat Pipe Operation, Front. Heat Pipes. 4 (2013) 13003. doi:10.5098/fhp.v4.1.3003.

[37] C.R. Deckard, Method and Apparatus for Producing Parts by Selective Sintering, 1989.

[38] L.E.. Murr, S.M.. Gaytan, F.. Medina, H.. Lopez, E.. Martinez, B.I.. Machado, D.H.. Hernandez, L.. Martinez, M.I.. Lopez, R.B.. Wicker, J. Bracke, Next-generation biomedical implants using additive manufacturing of complex, cellular and functional mesh arrays, Philos. Trans. R. Soc. A Math. Phys. Eng. Sci. 368 (2010) 1999-2032.

[39] G. Tapia, A. Elwany, A Review on Process Monitoring and Control in Metal-Based Additive Manufacturing, J. Manuf. Sci. Eng. 136 (2014) 60801. doi:10.1115/1.4028540.

[40] S.M. Thompson, L. Bian, N. Shamsaei, A. Yadollahi, An overview of Direct Laser Deposition for additive manufacturing; Part I: Transport phenomena, modeling and diagnostics, Addit. Manuf. 8 (2015) 36-62. doi:10.1016/j.addma.2015.07.001.

[41] N. Shamsaei, A. Yadollahi, L. Bian, S.M. Thompson, An overview of Direct Laser Deposition for additive manufacturing; Part II: Mechanical behavior, process parameter optimization and control, Addit. Manuf. 8 (2015) 12-35. doi:10.1016/j.addma.2015.07.002.

[42] L. Bian, S.M. Thompson, N. Shamsaei, Mechanical Properties and Microstructural Features of Direct Laser-Deposited Ti-6Al-4V, Jom. 67 (2015) 629-638. doi:10.1007/s11837-0151308-9.

[43] A.J. Sterling, B. Torries, N. Shamsaei, S.M. Thompson, D.W. Seely, Fatigue behavior and failure mechanisms of direct laser deposited Ti-6Al-4V, Mater. Sci. Eng. A. 655 (2016) 100-112. doi:10.1016/j.msea.2015.12.026.

[44] S.M. Thompson, Z.S. Aspin, N. Shamsaei, A. Elwany, L. Bian, Additive manufacturing of heat exchangers: A case study on a multi-layered Ti-6Al-4V oscillating heat pipe, Addit. Manuf. 8 (2015) 163-174. doi:10.1016/j.addma.2015.09.003. 
[45] T. Hao, X. Ma, Z. Lan, N. Li, Y. Zhao, H. Ma, Effects of hydrophilic surface on heat transfer performance and oscillating motion for an oscillating heat pipe, Int. J. Heat Mass Transf. 72 (2014) 50-65. doi:10.1016/j.ijheatmasstransfer.2014.01.007.

[46] M.J.. Rhodes, M.R.. Taylor, J.G.. Monroe, S.M. Thompson, Experimental Investigation of a Flat-Plate Oscillating Heat Pipe with Modified Evaporator and Condenser, ASME 2014 Int. Mech. Eng. Congr. Expo. (2014) IMECE2014-39188. doi:10.1115/IMECE2014-39188.

[47] L. Santodonato, H. Bilheux, B. Bailey, J. Bilheux, P.T. Nguyen, A.S. Tremsin, D.L. Selby, L. Walker, The CG-1D neutron imaging beamline at the Oak Ridge National Laboratory High Flux Isotope Reactor, Phys. Procedia. 69 (2015) 104-108.

[48] L. Crow, L. Robertson, H. Bilheux, M. Fleenor, E. Iverson, X. Tong, D. Stoica, W.T. Lee, The CG1 instrument development test station at the High Flux Isotope Reactor, Nucl. Instruments Methods Phys. Res. A. 634 (2011) S71-S74.

[49] M. Kang, H. Bilheux, S. Voisin, C. Cheng, E. Perfect, J. Horita, J.M. Warren, Water calibration measurements for neutron radiography: application to water content quantification in porous media, Nucl. Instruments Methods Phys. Res. Sect. A. 708 (2013) 24-31.

[50] Z.J. Zuo, M.T. North, K.L. Wert, High Heat Flux Heat Pipes for Cooling of Electronics, IEEE Trans. Components Packag. Technol. 24 (2001) 220-225.

[51] B. Holley, A. Faghri, Analysis of pulsating heat pipe with capillary wick and varying channel diameter, Int. J. Heat Mass Transf. 48 (2005) 2635-2651. doi:10.1016/j.ijheatmasstransfer.2005.01.013.

[52] E.W. Lemmon, M.O. McLinden, D.G. Friend, Thermophysical Properties of Fluid Systems, in: P.J. Linstrom, W.G. Mallard (Eds.), NIST Chem. WebBook, NIST Stand. Ref. Database 69, National Institute of Standards and Technolgy, Gaithersburg, n.d. http://webbook.nist.gov.

[53] M.H. Rausch, L. Kretschmer, S. Will, A. Leipertz, A.P. Fröba, Density, surface tension, and kinematic viscosity of hydrofluoroethers HFE-7000, HFE-7100, HFE-7200, HFE-7300, and HFE-7500, J. Chem. Eng. Data. 60 (2015) 3759-3765. doi:10.1021/acs.jced.5b00691.

[54] 3M, 3M Thermal Management Fluids: Cool Under Fire - Dielectric heat transfer fluid solutions for military and aerospace applications, (2009).

[55] A. Faghri, Y. Zhang, Transport Phenomena in Multiphase System, ElsevierAcademic Press, Burlington, 2006.

[56] A. Faghri, Y. Zhang, J. Howell, Advanced Heat and Mass Transfer, Global Digital Press, Columbia, 2010. 